\title{
Solid Thermochromism of Metal Chelates of Phthalein Dye in Polymer Matrix
}

\author{
Masato NANASAwa, ${ }^{*}$ Toshio Narita, and Hiroyoshi Kamogawa \\ Department of Applied Chemistry, Faculty of Engineering, \\ Yamanashi University, Kofu 400, Japan
}

(Received February 27, 1988)

\begin{abstract}
The solid thermochromism of metallophthalein was studied in the organic phase: 3,3-bis[bis(biscarboxymethyl)aminomethyl]phthalein derivatives, bivalent metal ions, and 3- or 4-substituted pyridines in polymer matrices. An intensive reversible color development (colorless $\rightleftarrows$ blue) by the application of heat was found for the nickel(II) chelate of cresolphthalein with 3-( $N$-alkyl)carbamoylpyridine in polar aprotic matrices. The bleaching rate in the matrices was strongly dependent on humidity. Thus, the cycle (color development, fixing, and bleaching processes) was controllable and repeatable.
\end{abstract}

KEY WORDS Thermochromism / EDRAW Memory / Triphenylmethane

Dye / Phthalein-Metal Complex /

Organic-erasable-direct-read-after-write (EDRAW) media has received much attention for its application to recording devices with high storage density and reliability. These include heating-mode recording systems employing the ablative recording of pigments ${ }^{1}$ and phase conversion recording of liquid crystals $^{2,3}$ in polymer matrices; both systems erase their memory by melting the recording layer through uniform heating of the films.

Although there has been studied a number of thermochromic compounds, ${ }^{4,5}$ no work has been done on EDRAW media using these compounds. Possibly, the thermochromic behavior takes place by a shift of equilibrium to a thermodynamically unstable colored state at an elevated temperture and this state tends to move to the original one at room temperature. This induces less reliability of image storage. However, if the equilibrium could be controlled by an external factor in the solid state, e.g., the solvation of unstable species with matrices, or if the reverse reaction should be frozen in polymer, EDRAW process using thermochromic compounds would become feasible.

We wish to report here the first study on the thermochromism of metallophthaleins in polymer matrices. Metal chelates with triphenylmethane dyes were found to indicate thermochromism by protolytic dissociation in aqueous Buffer solution. ${ }^{6,7}$ Since the reversible reaction takes place with a large difference of absorption maxima and metal chelates are stable to light and heating, solid thermochromism in polymer matrices is adequate for our purpose as an erasable memory.

For finding the thermochromism of phthalein complexes in organic phase, the following compounds were examined in organic solvents: 3,3-bis[bis(biscarboxymethyl)aminomethyl]phthalein derivatives, bivalent metal ions, and substituted pyridines as organic bases. The optimum conditions were applied to solid thermochromism in polymer matrices; their sensitivity of color development and stability of color species were investigated. 


\section{EXPERIMENTAL}

\section{Materials}

3- or 4-( $N$-Alkyl)carbamoylpyridines were prepared by aminolysis of 3- or 4-methoxycarbonylpyridine with the corresponding amines. 4-[N-(2-Hydroxyethyl)]carbamoylpyridine (4PyCONHEtOH): Yield 93\%; mp 125-127 ${ }^{\circ} \mathrm{C}$; IR (KBr), 3200-3300 (NH, OH), 1630 $(\mathrm{C}=\mathrm{O}) \mathrm{cm}^{-1} ;{ }^{1} \mathrm{H}$ NMR (dimethyl sulfoxide (DMSO- $d_{6}$ ), $\delta$ in ppm, 8.7 (d, 3H, 2-PyH, $\mathrm{NH}), 7.7$ (d, 2H, 3-PyH), 4.7 (t, 1H, OH), 3.5 (q, 4H, $\mathrm{CH}_{2}$ ). 3-PyCONHEtOH: Yield $83 \%$; mp 86-88 ${ }^{\circ}$ C. 3-PyCONHBu: Yield $85 \%$; mp $35-40^{\circ} \mathrm{C}$. Poly $(N$-vinyl-2-pyrrolidone) (PVP) and poly(vinyl alcohol) were purchased from Tokyo Kasei Co. $\left(M_{\mathrm{w}} 10,000\right)$ and Iwai Chem. Co. $\left(M_{w} 20,000\right)$, respectively. $\operatorname{Poly}(N, N-$ dimethylacrylamide) (PDMA) was obtained by the radical polymerization of its monomer in an aqueous solution, $[\eta]=1.7 \mathrm{dl} \mathrm{g}^{-1}$ at $25^{\circ} \mathrm{C}$ in water. All solvents were distilled under reduced pressure. Other chemicals were used as supplied.

\section{Measurement}

Visible spectra were recorded on a Hitachi 200-10 and a Shimadzu UV-160 spectrophotometer. Absorbance was measured for $0.1 \%$ dye solution in organic solvents containing a small amount of water $\left(1: 9 \mathrm{H}_{2} \mathrm{O}\right.$-solvent $)$ and also containing a 50 -molar equivalent base and 3-molar equivalent metal nitrate to one molar equivalent dye through $1 \mathrm{~cm}$ pass length at room temperature and $90^{\circ} \mathrm{C}$.

Films were prepared by spreading a solution of a matrix polymer $(30 \mathrm{mg})$, phthalein dye $(0.6 \mathrm{mg})$, and metal nitrate $(2.2$ fold molar ratio to dye) in water $(0.3 \mathrm{ml})$ containing organic base over a glass plate of $1.2 \mathrm{~cm}$ width so as to afford a $1.2 \times 2.0 \mathrm{~cm}^{2}$ area, followed by drying for two days at room temperature. The films, approximately $20 \mu \mathrm{m}$ in thickness, was then stored in a desiccator of anhydrous calcium chloride $(0 \% \mathrm{RH})$, or saturated sodium bromide solution $(58 \% \mathrm{RH})$ at least overnight before use. The film was heated at $90^{\circ} \mathrm{C}$ for $30 \mathrm{~s}$ on a hot plate, and the resulting color development was determined by transmission.

\section{RESULTS AND DISCUSSION}

\section{Thermochromism in Organic Solvents}

Triphenylmethane complexes show thermochromism by protolytic dissociation in aqueous media as shown in eq $1 .^{6}$ When the thermochromic process occurs in an organic phase, it would be affected by other factors, i.e., the solubility of metal complexes, equilibrium with organic bases, and solvation with organic media. For finding these effects, we examined thermochromism of cresolphthalein Complexon (PC) with 3- or 4- substituted pyridines $^{8}$ and bivalent metal ions $(\mathrm{Mg}$, $\mathrm{Mn}, \mathrm{Cu}$, and $\mathrm{Ni}$ ) in $N, N$-dimethylacetamide (DMAc), $N$-methylpyrrolidone (NMP), and ethylene glycol (EG).

\section{Metal Effect}

The intensive color development was obtained with $\mathrm{Ni}$ (II) ion for $\mathrm{PC}-3-\mathrm{PyCONH}_{2}$ system, but with other three metals, the absorbance at $90^{\circ} \mathrm{C}$ was small. This is related to the formation constant $(K)$ of analogous EDTA complexes with metals examined. ${ }^{9}$ The extent of complexation of PC dye is small for metals having low $K$-value such as $\mathrm{Mg}, \mathrm{Mn}$, and $\mathrm{Cu}$, in which uncomplexed PC-dye does not show any dissociation of phenolic proton with 3$\mathrm{PyCONH}_{2}$ even at elevated temperature. Absorbance at $600 \mathrm{~nm}$ heating at $90^{\circ} \mathrm{C}$ was also determined by the molar ratio method $^{6}$ for Ni-PC solution (Figure 1). The absorbance for a solution containing more than two fold excess of $\mathrm{Ni}$ over $\mathrm{PC}$ dye increased only slightly with large increase in the amount of $\mathrm{Ni}(\mathrm{II})$ ion. This suggests that thermochromism should take place by protolytic equilibrium within the 2:1 metal-PC complex in an organic solvent. 


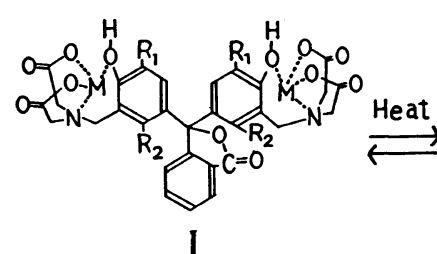

Colorless

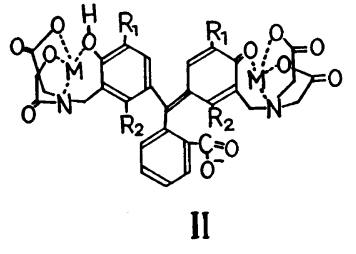

Colored

Table I. Absorbance of PC-Ni(II) chelate in the presence of various bases in polar organic solvents ${ }^{\mathrm{a}}$

\begin{tabular}{|c|c|c|c|c|c|c|c|}
\hline \multicolumn{2}{|l|}{$\begin{array}{l}\text { Solvent }{ }^{\mathrm{b}} \\
\alpha_{\max } / \mathrm{nm}\end{array}$} & \multicolumn{2}{|c|}{$\begin{array}{c}\text { NMP } \\
600\end{array}$} & \multicolumn{2}{|c|}{$\begin{array}{c}\text { DMAc } \\
600\end{array}$} & \multicolumn{2}{|c|}{$\begin{array}{l}\text { EG } \\
595\end{array}$} \\
\hline Base $\left(\mathrm{p} K_{\mathrm{a}}\right)$ & & $A_{0}$ & $A_{\mathrm{h}}$ & $A_{0}$ & $A_{\mathrm{h}}$ & $A_{0}$ & $A_{\mathrm{h}}$ \\
\hline 3-PyCN & $(1.95)$ & 0 & 0.14 & 0 & 0.23 & 0 & 0 \\
\hline 4-PyCOOMe & $(2.65)$ & 0 & 0.34 & 0 & 0.25 & 0.03 & 0.17 \\
\hline 4-PyCONHR & (3.1) & 0.02 & 1.32 & 0.02 & 0.72 & 0.19 & 0.66 \\
\hline 3-PyCONHR & (3.6) & 0.02 & $>2$ & 0.02 & 1.42 & 0.25 & 1.85 \\
\hline 3-PyNHAc & $(4.0)$ & 0.32 & $>2$ & 0.02 & $>2$ & $>2$ & \\
\hline 3-РyOH & $(4.5)$ & 0.06 & $>2$ & 0.10 & $>2$ & & \\
\hline Py & $(5.3)$ & $>2$ & & $>2$ & & & \\
\hline
\end{tabular}

a $A_{0}$, absorbance at room temperature, $A_{\mathrm{h}}$, at $90^{\circ} \mathrm{C}$. 3-Cyanopyridine is abbreviated as 3-PyCN, and so on $(\mathrm{R}=$ $-\mathrm{EtOH})$.

b NMP, $N$-methylpyrrolidone; DMAc, $N, N$-dimethylacetamide; EG, ethylene glycol.

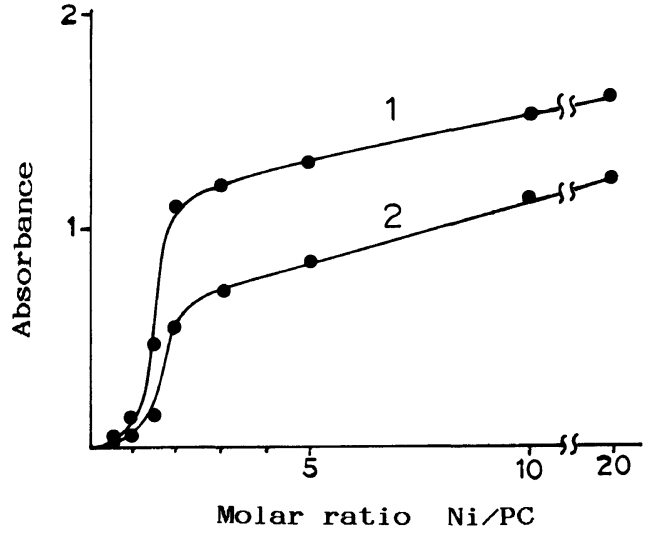

Figure 1. Molar ratio method of absorbance at $600 \mathrm{~nm}$ for $\mathrm{PC}-\mathrm{Ni}$ complexes at $90^{\circ} \mathrm{C}: 1,0.025 \% \mathrm{PC}$ with pyridine in $N, N$-dimethylacetamide; $2,0.1 \%$ PC with nicotinamide in $N$-methylpyrrolidone.

\section{Effects of Basicity and Kind of Solvent}

Table I shows the thermochromism of PC$\mathrm{Ni}$ chelates with various pyridine derivatives. Since color development takes place by dissociation of phenolic protons from $\mathrm{PC}-\mathrm{Ni}$ chelate, its absorbance depends on the stability of a combination of metalloquinonoid anion (II in eq 1) and protonated pyridine derivative. The salt composed of the metalloquinonoid anion and a low $\mathrm{p} K_{\mathrm{a}}$ pyridinium cation such as protonated 3-cyanopyridine $\left(\mathrm{PyCNH}^{+}\right)$is not very stable and thus its absorbance is small at $90^{\circ} \mathrm{C}$. The stability of the salt with the protonated pyridine $\left(\mathrm{PyH}^{+}\right)$is much higher than its free state (metallophthalein-Py), so that the equilibrium lies far to the right even at a low temperature. The optimum $\mathrm{p} K_{\mathrm{a}}$ value of pyridine derivatives affording a large temperature dependence is between 3 and 4 .

Thermochromic behavior is also affected by the kind of organic solvent. The temperature dependence is small in a polar protic solvent compared with that in an aprotic one. Since EG, a strong protic solvent, solvates both the carboxylate anion and counter cation in a metalloquinonoid-pyridine derivative combination strongly and increases the content of the anion, strong absorption is induced even at 


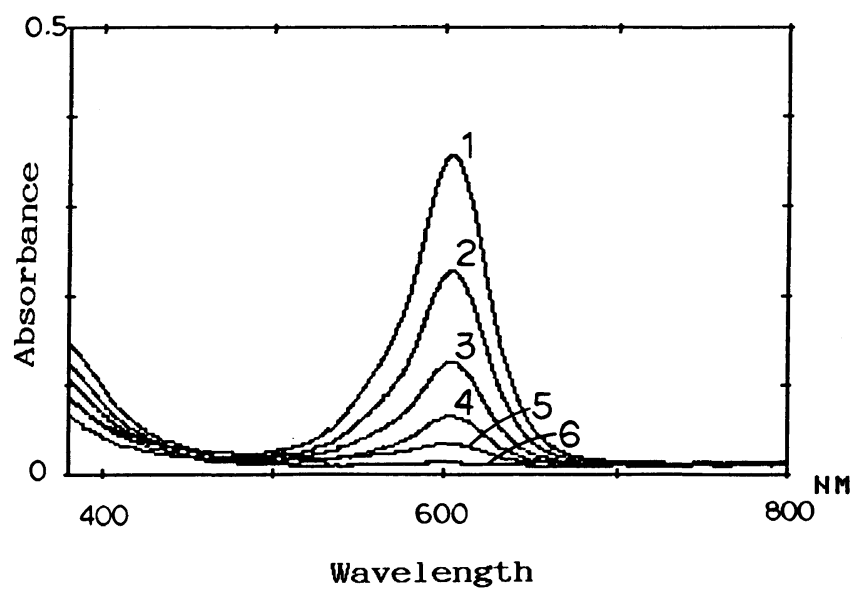

Figure 2. Spectral change of PC-Ni-PVP film containing 3-PyCONHEtOH: 1, immediately after heating; $2,3,4,5$ curves obtained at $1,3,6$, and $10 \mathrm{~h}$ after heating, respectively; 6 , before heating and after recovery at $58 \% \mathrm{RH}$.

Table II. Thermochromism of PC-Ni(II) chelate in polymer matrices containing various bases ${ }^{\mathrm{a}}$

\begin{tabular}{|c|c|c|c|c|c|c|c|}
\hline \multirow{2}{*}{$\begin{array}{c}\text { Matrix polymer } \\
\mathrm{RH}^{\mathrm{c}} / \%\end{array}$} & & \multicolumn{2}{|c|}{ PVP } & \multicolumn{2}{|c|}{ PDMA } & \multicolumn{2}{|c|}{ PVA } \\
\hline & & 0 & 58 & 0 & 58 & 0 & 58 \\
\hline \multicolumn{8}{|l|}{ Base } \\
\hline \multirow[t]{2}{*}{ 4-РyCOOME } & $A_{0}$ & 0 & 0 & & 0 & 0.30 & 0.22 \\
\hline & $A_{\mathrm{h}}$ & 0.01 & 0.01 & & 0.03 & 0.88 & $>2$ \\
\hline \multirow[t]{2}{*}{ 4-PyCONHEtOH } & $A_{0}$ & 0.01 & 0 & 0 & 0 & 0.48 & 0.31 \\
\hline & $A_{\mathrm{h}}$ & 0.11 & 0.16 & 0.03 & 0.12 & $>2$ & $>2$ \\
\hline \multirow[t]{2}{*}{ 3-PyCONHEtOH } & $A_{0}$ & 0.01 & 0 & 0.01 & 0.02 & & \\
\hline & $A_{\mathrm{h}}$ & 0.28 & 0.35 & 0.19 & 0.20 & & \\
\hline \multirow[t]{2}{*}{ 3-PyCONHBu } & $A_{0}$ & 0.02 & 0.01 & 0.01 & 0.01 & & \\
\hline & $A_{\mathrm{h}}$ & 0.52 & 0.81 & 0.21 & 0.44 & & \\
\hline \multirow[t]{2}{*}{ 3-PyNHAc } & $A_{0}$ & 0.02 & 0.02 & 0.04 & 0.05 & & \\
\hline & $A_{\mathrm{h}}$ & 0.37 & 0.46 & 0.26 & 0.36 & & \\
\hline \multirow[t]{2}{*}{ 3-РyOH } & $A_{0}$ & 0.28 & 0.18 & 0.11 & 0.15 & & \\
\hline & $A_{\mathrm{h}}$ & 0.77 & 0.80 & 0.38 & 0.65 & & \\
\hline
\end{tabular}

a The molar ratio of base to PC-dye is 40 .

b PVP, poly( $N$-vinyl-2-pyrrolidone); PDMA, poly( $N, N$-dimethylacrylamide); PVA, poly(vinylalcohol).

c $\mathrm{RH}$, relative humidity.

low temperature. ${ }^{10}$ Polar aprotic solvents tend to predominantly solvates the pyridinium cation formed by protonation at elevated temperature, compared with the undissociated metallophthalein having bulky molecular size, thereby stabilizing the colored state. This causes the large temperature dependence of thermochromism in aprotic solvents.

\section{Thermochromism in Polymer Matrices}

Figure 2 and Table II show the thermochromism of phthalein-nickel(II) chelate with pyridine derivatives $\left(\mathrm{p} K_{\mathrm{a}} 2.6-4.0\right)$ in PVP, PDMA, and PVA matrix films. Since thermal molecular motion is highly restricted in the solid state and the reaction occurs bimolecularly for metallophthalein-base combination, the progress of the reaction may pos- 


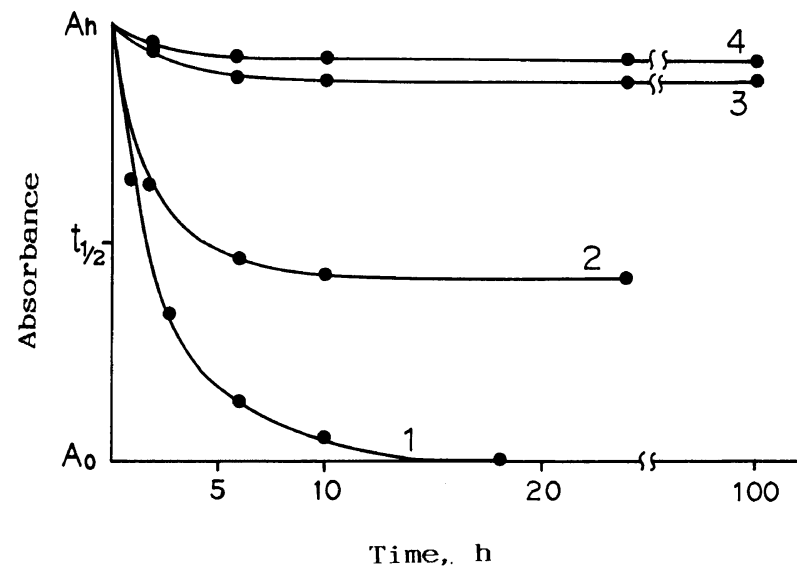

Figure 3. Stability of metalloquinonoid in PVP-matrix: 1, containing 3-PyCONHEtOH (40) at 58\% RH; 2, 3-PYCONHEtOH (80); 3, 3-PyCONHBu (40); 4, 3-PyCONHEtOH (40) at $0 \% \mathrm{RH}$; the number in parentheses shows the molar ratio of pyridine derivative to the dye.

sibly be hindered to a considerable extent. However, films were cast from an aqueous solution in which metallophthaleins and bases may exist as solvated ion pairs. Therefore, two components might be present very close together in a polymer matrix after evaporation of water. Color development was brought about by heating the film above the glass transition temperature of the matrix polymer, and thus the bimolecular reaction was possible in the solid state.

The effects of matrix and basicity of pyridine derivative on the thermochromism are similar to those in an organic solvent: the higher basicity and larger molar ratio of the base to metallophthalein increase the shift of the equilibrium position to the right. A film using poly(vinyl alcohol) (PVA) as a matrix is highly colored at room temperature even with use of a base of lower basicity. Protic matrix binds both the anion and cation of the ion pair, so that the pair might be fixed tightly to the solid protic matrix after evaporating the solvent, water, even at low temperature: On the other hand, aprotic matrix tends to bind the pyridinium cation preferentially and causes a low concentration of the anion at low temperature, so that a higher temperature is required to attain a concentration of the anion enough to develop a strong color. Moisture included in the films acts as a plasticizer, which induces intensive color development at higher RH.

\section{Bleaching rate}

Figure 3 exemplifies absorbance change with time of the color-developed films stored in a $0 \%$ or $58 \%$ RH desiccator. The half recovery time $\left(t_{1 / 2}\right)$ is less than several hours in the case of films stored at $58 \% \mathrm{RH}$ or films containing a large amount of base possessing a low melting point such as 3-PyCONHBu, whereas the developed color is stable at $0 \% \mathrm{RH}$ for more than half a year and can be bleached by bringing to $58 \% \mathrm{RH}$.

The back reaction (color bleaching) is much influenced by the physical properties of films regardless of the basicity of bases included in the films: moisture and the base of low melting point increase the bleaching rate by the plasticizer effect; on the other hand, the back reaction between metalloquinonoid anions and tightly solvated pyridinium cations is highly restricted in a glassy aprotic matrix without moisture. Thus, image storage is possible. The cycle (color development, fixing, and bleaching processes) was controllable and repeatable. Thus, the thermochromism of metallophthalein in aprotic matrices is promising for the 
use as an EDRAW memory.

\section{REFERENCES AND NOTES}

1. A. Kuroiwa, K. Nanba, S. Asami, T. Aoi, K. Takahashi, and S. Nakagawa, Jpn. J. Appl. Phys., 22, 340 (1983).

2. H. J. Coles, Polym. Sci. Technol., 28, 351 (1985).

3. T. Ueno, T. Nakamura, and T. Tani, Preprint of Spring Meeting of Jpn. Appl. Phys., 4P-B-14 (1986).

4. J. H. Day, Chem. Rev., 63, 65 (1963).

5. K. Maeda, J. Synth. Org. Chem. Jpn., 44, 431 (1986).

6. S. Nakada, M. Yamada, T. Ito, and M. Fujimoto,
Bull. Chem. Soc. Jpn., 52, 766 (1979).

7. S. Nakada, T. Ito, M. Yamada, and M. Fujimoto, Bull. Chem. Soc. Jpn., 54, 2913 (1981).

8. An optimum $\mathrm{pH}$ range in aqueous solution are between 4.8 and 6.4 (ref 6). 3- or 4-Substituted pyridines were employed as organic base due to moderate basicity and good solubility; their dissociation constants were calculated from Hamett equation.

9. L. G. Sillen and A. E. Martell, "Stability Constants of Metal-Ion Complexes," 2nd ed., The Chemical Society, London, 1964.

10. D. A. Hinckley, P. G. Seybold, and D. P. Borris, Spectrochim. Acta, 42A, 747 (1986). 